FACULdAde de FormaÇÃo de PROFESSORES

\title{
TRAÇOS DO DECADENTISMO NA POESIA BRASILEIRA DE 1880 A 1920: RAIMUNDO CORREIA E GILKA MACHADO
}

\author{
Fernando Monteiro de Barros (UERJ) \\ fermonbar@uol.com.br \\ Aline Pereira (UERJ) \\ Suzane Morais da Veiga (UERJ)
}

\begin{abstract}
A literatura brasileira do final do século XIX, influenciada pelo esteticismo finissecular europeu, apresenta uma oscilação estilística que a entrelaça ao contexto de transição e efervescência do período. Segundo aponta José Guilherme Merquior, no Brasil os estilos literários posteriores ao Romantismo foram "mais simultâneos que sucessivos" (1996, p.141) acarretando, no contexto do fim do século e da Belle Époque, em uma pluralidade estética que se pode verificar na profusão de estilos por vezes mais convergentes do que divergentes. Assim, o Parnasianismo brasileiro, que data da década de 1880 e se espraia até o advento do Modernismo, apresenta aspectos diversos que explodem em variadas faces, dentre as quais destacamos aqui a face decadentista, na obra poética de Raimundo Correia (18591911), autor que figura como um dos fundadores do nosso Parnasianismo.
\end{abstract}

Diferentemente da Europa, já transformada pela indústria, o Brasil sustentava e era sustentado pelo escravismo que convivia com ideias liberais e que pouco se modificou após a República, com a manutenção do coronelismo e das oligarquias, de modo que não podemos propriamente falar em uma "burguesia" brasileira daquele tempo tal qual a europeia e a norte-americana. A complexidade do período é sublinhada pelas contradições da crítica literária, levando a crer, como assinala Ivan Junqueira no ensaio que introduz sua tradução de As Flores do Mal, de Charles Baudelaire (1985, p. 59), que o Parnasianismo, enquanto escola literária, não tenha configurado-se muito nitidamente entre nós. Desse modo se levanta aqui uma problemática a partir da ausência, na historiografia literária brasileira, da ocorrência da estética decadentista. 
Tanto na poética parnasiana como na literatura decadentista privilegia-se o momento da produção e tende-se a substancializar o belo artístico na obra, mas, no Decadentismo, a violação dos tabus, o contraste, a "tematização dos desvios e das exceções" (LEVIN, 1996, p. 35), a busca do novo nos estados anormais, o artificialismo como princípio e o repúdio à natureza, apontam para um esteticismo levado às últimas consequências que flerta com a maldição. Dentre as manifestações decadentistas na literatura brasileira, inicialmente focalizaremos parte da obra Versos e Versões (1887), de Raimundo Correia.

Os poemas deste livro apontam para a inquietação filosófica e a amargura típica dos céticos, traços que caracterizaram a obra do poeta maranhense em sua fase mais madura. Com uma ironia elegante, o autor persegue o tema da ambiguidade humana, a reticência e a imensidão intransponível do mistério que permeiam a natureza, a vida e a morte. Contudo, ao hermetismo aristocrático que traduz o desprezo pela realidade massificante, contrapõe-se o olhar analítico da época realista. O mistério estimado no livro é familiar, por exemplo, ao de Guy de Maupassant e Machado de Assis. Assim, a consciência de uma realidade intransponível é também a consciência do abismo da alma do poeta. Nos versos de poemas como "Job"

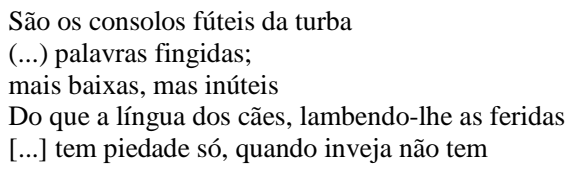

e "O misantropo" ("É preciso odiar para ser justo?!"), entrevemos o repúdio ao homem e à sociedade de seu tempo. Escapando aos moldes rígidos do Parnasianismo francês, a escrita de Raimundo Correia oscila entre a superfície e a profundidade, sobrepondo-se nela o espírito contemplativo, prescrito pelos estetas posteriores ao Romantismo. Do Decadentismo, as imagens da agonia, num fazer artificial de quadros outonais, crepusculares e macabros, acompanhados pelo vício heráldico da perversão, o erotismo sádico, sempre acompanhado da mulher fatal de matiz baudelairiana, o horror, a exploração da beleza misteriosa e o jogo de contrastes, quando foge ao predomínio da oposição simbolista imanência/transcendência. 
Raimundo Correia traduziu autores celebrados, entre os quais Theophile Gautier e Leconte de Lisle, e enriqueceu nosso vocabulário poético com as imagens da "nevrose" e do "túmulo". Preso à sua época e ao mesmo tempo preso ao devir, Correia absorvera o pessimismo de Schopenhauer, a quem o artista dedica versos como:

Jamais do lábio irônico e sombrio

A alma te veio à flor; sempre sereno

Sorriste... Os animais de sangue frio são os que têm mais veneno.

O gosto pelo simulacro é carregado de morbidez, em que figuram a "carne decomposta", a clausura, a "asfixia", o pesadelo, o fantasmagórico, apontando para certa influência de Edgar Allan Poe. No poema "A filha do coveiro", tanto a influência de Rollinat, como da teoria mística das correspondências, de Baudelaire, indicam a lateralidade de Poe, sem, de modo algum, subtrair a originalidade do brasileiro que buscou, através da poesia, correlacionar todas as artes. $\mathrm{Na}$ escultura laboriosa da forma verbal e na perseguição do belo "correto", imperceptível às lentes da máquina, Correia embala as palavras afinadamente, em versos musicais e imagéticos, e a fantasia muitas vezes ganha espaço na exploração da beleza horrível, resultado da elaboração e do cálculo. O erotismo sofisticado e perverso do autor, como em Baudelaire, faz o amor assemelhar-se a uma tortura e, assim, o espectro da "paixão criminosa" da mulher fatal dá o tom das variações sádicas na obra, simultaneamente à fusão dos contrastes branco/vermelho, vítima/carrasco, belo/horrível, raro/vulgar, dor/prazer, num balé sinestésico, em prol da sugestão. Os "olhos de lascívia e de volúpia", em "Aspásia", sugerem uma perspectiva de amor que apavora, e que vemos se repetir semelhantemente em "Tentações do ermo" e em "O monge":

Quando eu, porém, falei no amor, um riso

Súbito as faces do impassível monge

Iluminou... Era o vislumbre incerto,

Era a luz de um sol que já vai longe,

$\mathrm{E}$ as sombras de uma noite que vem perto!...

Influenciado pelo movimento de ruptura da modernidade francesa, Raimundo Correia ajuda a consolidar a "nova geração" literária do Brasil e, a exemplo dos decadentistas, recusa o sufocante encarceramento da razão. O poeta brasileiro sofria entre a matéria e o infinito, refugiando-se no mundo imaginário, ou em épocas passadas, 
e atribuindo seu culto à arte como via de erudição, num universo onde a beleza se impôs como o critério moral. A poesia de Raimundo Correia aproxima-o de Baudelaire, que permitiu dar a imagens assustadoras uma beleza misteriosa. Nos versos de "Fetichismo", a voz poética "da vida as sombras inclementes", debalde se indaga: "Que céus habita Deus?". A "dúvida atroz blasfema e grita" e "tudo em torno de trevas" fazem com que a única coisa palpável seja o vácuo. "Anoitecer" sugere a agonia do Ocidente, em que se fecha "a pálpebra do dia" e

em tudo, em torno, esbatem derramados

Uns tons suaves de melancolia.

Mas é na exploração do belo grotesco que Raimundo Correia mais se aproxima do Decadentismo. O ar saturado, aborrecido, dominador, voluntarioso, indecente, frio; o ar perverso, doentio, felino, malicioso; os encantadores ares da mulher, que Baudelaire proclamou como sendo ares de beleza, todos estão presentes na obra poética do brasileiro ao explorar o estereótipo da efígie feminina. Datado de 1886, o poema "Desdéns" evidencia o contraste simbólico das cores, o culto dos objetos, a alteração dos sentidos, o erotismo sadomasoquista, em que a mulher metamórfica e indiferente é traçada metonimicamente, sobretudo pelas mãos fidalgas, de pele fina e branca e unhas vermelhas, sangrentas. Por intermédio da imaginação, a imagem feminina provoca os sentidos, impondo sobre a voz poética impassivelmente a dor da morte lenta. Sensualmente sedutora, a mulher se transforma em felino, ideal de beleza, elegância e voluptuosidade. As artificiais "unhas de coral" são convertidas em garras, com as quais ela tem o prazer de matar aos poucos. O sândalo, inebriante apelo sinestésico, e a ventarola de marfim, adorno feminino com que se abana teatralmente, são parte do universo de simulacros a representar uma ação antinaturalista de recriação do mundo.

$\mathrm{O}$ ar cheiroso em redor se desenrola;

Pulsam os seios, arfam as narinas...

A distinção nobre é um atributo da fêmea fatal, que se inclina numa indolência mórbida sobre o espaldar de seda. O sadismo da mulher é satisfeito pelo drama das reações antagônicas que impõe à voz poética.

Essa mão, que me atrai e me afugenta,

Que eu afago, que eu beijo, e que me espanca! 
As metáforas dos tercetos se estruturam em imagens de violência e submissão. A ambiguidade dos movimentos da mulher, indolentes e frenéticos, calculados e animalescos, de uma crueldade adorável, inspira o dualismo de sentimentos de idolatria mórbida. Essa relação pode ser feita de modo semelhante no poema "Garra Oculta".

Desse modo, a lírica raimundiana aponta para o sincretismo estético e, especificamente, para a incoerência de alienar da nossa historiografia literária o Decadentismo, marcado pela pose e o desejo de escandalizar, num sentido transversal ao menosprezo dedicado à escola.

Poucas décadas depois, já no início do século XX, a Belle Époque carioca testemunhou o nascer de flores raras da literatura brasileira, dentre as quais Gilka Machado (1983-1980) se destaca de forma exemplar. Poucas vezes havia-se visto no cenário nacional uma escritora com tamanha força lírica e que soubesse cantar com tanta veemência o clamor da condição feminina de sua época. Epígona de Charles Baudelaire (1821-1867), recebe grande influência do mestre francês principalmente no que tange à adesão ao paradigma da femme fatale como leitmotiv de seus poemas. Dessa maneira, a mulher na obra de Gilka se revela como sujeito de seu desejo sexual, o que distingue o eu lírico gilkaniano. Transgressora, em meio a uma sociedade misógina e patriarcal, Gilka provoca furor com a publicação de poemas dotados de um desejo erótico surpreendente, nos quais Eros revela-se com força total.

No Brasil do início do século XX, o puritanismo, as preocupações morais, o rigor das convicções religiosas, os preceitos sociais, em suma, a exigente e rígida cultura da burguesia exigia de homens e, principalmente, de mulheres, uma reserva erótica. A mulher vivia numa sociedade patriarcal e misógina, na qual, para o homem, como afirma Elisabeth Badinter (1986, p.125), a mulher tem, triplamente, o status de objeto. Ao mesmo tempo, é um instrumento de promoção social (casamentos por interesse), eventualmente um objeto de distração, e um ventre do qual se toma posse.

Dotada de uma extrema irritação antiburguesa, Gilka ficou, e ficará sempre como exemplo, isolado em seu tempo, de corajosa transgressão das expectativas sociais com respeito à mulher. Feminista, avant la lettre, rebelde, sua poesia é de revolta e inconformis- 
mo social, mas também, para usar a expressão de Eugênio Gomes, da "intensidade". Assim, ela possui todas as características do pioneirismo de um lirismo de primeira água, como raros na Belle Époque.

Natural do Rio de Janeiro, Gilka Machado nasceu no dia 12 de Março de 1893. Casou-se com o poeta Rodolfo de Melo Machado em 1910 e juntos tiveram dois filhos: Hélios e Eros. Faleceu no Rio de Janeiro capital, no dia 11 de Dezembro de 1980. Sua obra poética inaugura-se em 1915 com o lançamento do seu primeiro livro de poemas Cristais Partidos.

Dona de uma extensa produção literária, Gilka foi alvo de muitas críticas com o lançamento do seu primeiro livro, sobretudo por ter explorado com ousadia a temática do desejo erótico e desafiado, assim, o "interdito ao corpo". Assim, como afirma Andrade Muricy no prefácio de suas Poesias Completas, "o mito duma sensualidade a todo custo formou-se, fruto do mesmo preconceito que tem atingido, através dos séculos, a tantas obras nas quais o corpo ousou cantar o seu maravilhamento de ser, mas também de sentir" (MURICY, apud MACHADO, 1991).

A natureza do preconceito recebido por Gilka, ainda segundo Andrade Muricy, se daria ao fato da não compreensão pelos leitores e, via de regra, da crítica da época, de sua proposta poética, dotada de uma nova concepção e percepção do erotismo do corpo. Essa abordagem, como explicita o autor, não é nova uma vez que sempre, ao longo dos séculos, qualquer tentativa de se explorar a sensualidade erótica sofreu uma forte crítica por parte de seus contemporâneos. Dessa forma, Gilka filia-se visceralmente ao que Baudelaire fizera algumas décadas antes, na burguesa França oitocentista, em versos que provocaram grande polêmica e que foram, efetivamente, um divisor de águas na instauração de uma nova visão sobre a literatura.

A escrita de Gilka Machado expressa o sincretismo finissecular (fusão de Parnasianismo, Decadentismo e Simbolismo) fruto da transição literária na qual ela estava inserida. Esse período é a chamada Belle Époque que no Brasil situa-se entre 1889, com a proclamação da República, até 1922, ano da Semana de Arte Moderna. Nessa fase, surgem poetas novos, epígonos parnasianos e simbolistas, os quais se distinguem por herdar traços tanto de uma quanto da outra escola literária, abrindo-se, assim, vários rumos. Contra o zeit- 
geist realista, positivista, evolucionista, a poesia de Gilka Machado encontra-se mesclada por elementos então em voga na época, destacando-se os advindos do Decadentismo, os quais contribuem não só na temática como inclusive em requisitos formais, como na liberdade rítmica.

Análoga a Baudelaire, Gilka Machado desenvolve uma escrita permeada por um erotismo escaldante, através de uma explosão de sexualidade. Conforme afirma Foucault (1976, p. 13): "se o sexo é reprimido, isto é, condenado à proibição, à inexistência e ao mutismo, o único fato de se falar sobre o assunto e de se falar de sua repressão, adquire uma aragem de transgressão deliberada"; assim, percebemos que a insatisfação social, a sexualidade e a literatura vêm sempre acompanhados nos momentos mais críticos da sociedade. Com isso, em ambas as obras, há a representação da mulher fálica - a mulher fatal - em pleno controle de sua sexualidade.

Dessa maneira, o eu lírico feminino gilkaniano situa-se como sujeito do desejo sexual, como uma mulher desejante. Por conseguinte, ela usa o sensualismo erótico como afirmação da sexualidade da Mulher, trazendo sobre si os anseios e desejos de todas as mulheres ("Rosas"):

Seja qualquer a cor, por sobre o hastil de cada Rosa, vive a Mulher, nos jardins flor tornada: - símbolo da Volúpia a excitar o Desejo.

Dai que eu possa gozar, ao vosso colo rente,

Esse perfume a um tempo excitante e emoliente,

Numa dúbia, sensual e suave sensação!

Essa caracterização da mulher como detentora da Volúpia, desejante em concretizar as palpitações de seu Desejo por desabrochar qual flor exibindo-se em um jardim, é muito próximo ao Ideal de mulher - fatal - procurada pelo eu lírico baudelairiano ("O Ideal"), como podemos entrever nestes versos do poeta d'As flores do mal: 
Jamais serão essas vinhetas decadentes,

Belezas pútridas de um século plebeu

Nem borzeguins ou castanholas estridentes,

Que irão bastar a um coração igual ao meu.

Concedo a Gavarni, o poeta das cloroses,

Todo o rebanho das belezas de hospital,

Pois nunca vi dentre essas pálidas necroses

Uma só flor afim de meu sanguíneo ideal. (BAUDELAIRE, 1985)

É mister mencionar as várias personas femininas criadas por Gilka. Como afirma Massaud Moisés (1984, p.257) ora será fauve, notadamente em se tratando de cores como em "Emotividade da Cor"; ora satânica ou vampiresca em seus arranques passionais como no poema "Volúpia"; ora entediada ("Conjecturando") ou como uma doente, decadente ("Canção de uma doente"). Nessa cisão megalomaníaca do "eu" em duplos ou múltiplos, ela consegue, através das angústias e sofrimentos individuais, traçar ontologicamente a agonia (das mulheres e mais tarde de toda sorte de oprimidos) de uma sociedade decadente. Essa tendência, sem dúvida magistralmente trabalhada por Baudelaire em seus poemas, é no que consiste a modernidade da poesia de Gilka Machado, cujo espólio poético apresenta material singular da tentativa de fuga da trivialidade do real até as mais distantes zonas do misterioso e do poético.

A transgressão do proibido caminha de mãos dadas com o erotismo. O pecado e o desejo da carne geram conflitos interiores entre o pudor (determinado pela moral e religião) e o prazer obtido no desejo erótico. Como nos diz Otávio Paz (1994, p. 18) "Em todas as sociedades há um conjunto de proibições e tabus - também de estímulos e incentivos - destinados a regular e controlar o instinto sexual"; assim, a prática sexual do homem passou a ter sua frequência regulada pela religião e pela sua disponibilidade para o trabalho. O desejo foi minimizado para que houvesse o equilíbrio essencial à atividade do homem em sociedade. Os instintos sexuais foram ligados à animalidade e, consequentemente, repelidos pelo homem ao lhes atribuir um caráter maligno colocando-os no universo das proibições e das "decadências" humanas.

Dessa maneira, a mulher aparece na literatura baudelairiana como a figura primordial detentora do desejo erótico e, por isso, contendo um aspecto maligno e transgressor, pois se entrega aos instin- 
tos primevos do ser humano. Da mesma maneira, Gilka Machado, em sua produção poética, apreende o paradigma da mulher fatal baudelairiana, a fim de definir os contornos externos de uma autonomia poética que até então não se conhecia em literatura de autoria feminina. A poeta encena uma dupla geografia do estado do ser feminino, retratando, a princípio, o prazer no avesso do corpo, na matriz do imaginário, no ambiente das ideias, dos sonhos e sentimentos represados. Assim, expressa o desejo no terreno externo do corpo, espaço assumido pela exposição real dos sentimentos e desejos humanos interditados às mulheres de sua época, pelo menos às chamadas "moças de família". Daí, o caráter transgressor de sua obra, na medida em que leva o seu interlocutor a desviar-se do paradigma hierarquizante homem/mulher, o qual durante todo o trajeto da construção poética da autora é levado a ser demolido, mas sem descaracterizar a mulher de suas especificidades femininas, levando a um complexo diálogo dialético com o masculino a quem o eu lírico feminino se reporta.

Esse trabalho poético empreendido por Gilka (e também por outras mulheres da época) foi uma espécie de mola propulsora para uma conscientização da produção artística feminina que, mais tarde, seria talvez o fenômeno mais significativo da Literatura na segunda metade do século XX. Assim nos confirma Nelly Novaes Coelho, em relação à transgressão do cânone patriarcal, ressaltando ser

Inegável que, mais que os estudos das ciências sociais, a literatura tem sido um dos grandes instrumentos conscientizadores. Desde as vozes pioneiras que, na poesia do início do século, se assumiam como "transgressoras" (Colombina, Gilka Machado, Pagu) até nossos dias, a literatura vem dando voz a uma nova consciência da mulher, não só em relação a si mesma (...), mas também em sua tarefa na construção da História. (COELHO, 1999, p. 11)

Na poesia de Gilka há um apelo a uma sensualidade tátil, visual, de todos os sentidos, cuja matriz encontra-se em Baudelaire. Podemos notar este aspecto no poema intitulado "Perfume" comparando-o ao poema baudelairiano que carrega o mesmo nome. Em ambos é possível notar a temática do perfume como acesso a um estado misterioso e revelador: 


\section{DEPARTAMENTO DE LETRAS}

Vaga revelação das sensações secretas, Das mudas sensações dos mudos vegetais;

Arco abstrato que afina as emoções dos poetas

E que ao violino da alma arranca sons iriais.

Ó perfume que a dor das plantas interpretas

E encerras, muita vez, desesperos mortais!

Busco sempre sentir-te errar, nas noites quietas,

Quando teu flóreo corpo em sono imerso jaz. (GILKA MACHADO)

Conduz-me o teu perfume às paragens mais belas;

Vejo um porto ideal cheio de caravelas

Vindas de percorrer países estrangeiros

E o perfume sutil do verde tamarindo,

Que circula no ar e que eu vou exaurindo,

Vem juntar-se em minh'alma à voz dos marinheiros.

(BAUDELAIRE, 1985, p. 157)

Assim, objeto principal é o corpo sensível, o corpo sensual no qual o eu lírico procura sensações inéditas, refinadas, usando da contemplação ("Canção de uma Doente"):

Ao pôr do sol de uma Quimera,

De uma Quimera ao sol se pôr.

Porém, ao se aprofundar no erotismo em busca de uma resposta à libertação do "eu", essa vontade não é saciada e, como em Baudelaire, traz um vazio, fazendo com que o eu lírico caia no Nada e comece a contemplar a si mesmo e ao mundo com extremo Tédio. A única solução é a morte - as Trevas - e a esperança de "encontrar no Ignoto o que tem de novo", como afirma Baudelaire ("A Viagem"):

Ó Morte, velho capitão, é tempo! Às velas!

Este país enfara, ó Morte! Para frente!

Se o mar e o céu recobrem o luto das procelas,

Em nossos corações brilha uma chama ardente!

Verte-nos teu veneno, ele é que nos conforta!

Queremos, tal o cérebro nos arde em fogo,

Ir ao fundo do abismo, Inferno ou Céu, que importa?

Para encontrar no Ignoto o que ele tem de novo!

(BAUDELAIRE, 1985, p. 441) 
Nem risos de prazer nem ais de angústia: nada.

- Dia para o sabor do Tédio, tão somente.

A atmosfera recorda água morna e estagnada. (Gilka MACHADO).

\author{
Mas tu, Sono, me dás a inefável delícia \\ De ensaiar a escalada \\ Para a Morte - a ascensão à glória ambicionada; \\ Mas tu, Sono, és a calma, és a mudez propícia \\ À suave antevisão da ampla Canaã do Nada. (GILKA MACHADO).
}

$\mathrm{Na}$ verdade o que poetas como Baudelaire e mais tarde Gilka percebem é "um certo ar de cansaço, uma vaga ideia de algo que morre, um mundo em decomposição" como afirma Fúlvia Moretto (1989), indo contra as ideias realistas, positivistas da Belle Époque. Esperam, assim, encontrar algo de novo em algum lugar diferente do mundo em ruínas no qual eles se perceberam vivendo.

O erotismo na obra de Gilka Machado é fonte de afirmação e libertação e está fortemente marcado pelo Decadentismo fin-desiècle, o mesmo que fora motivado pelos poemas de Baudelaire. Principalmente por se ver subjugada pelos rígidos padrões morais da época e incomodada pela falsa aparência de estufa de sua época, a escrita de Gilka é como um grito de denúncia da decadência da sociedade carioca de seu tempo, pintando imagens de uma nova Mulher multiforme, multicor. Assim, liberdade e opressão, amor e erotismo, vida e morte, verso e reverso se fundem na poética desse caleidoscópio chamado Gilka Machado.

\title{
BIBLIOGRAFIA
}

BADINTER, Elisabeth. Um é o outro; Relações entre homens e mulheres. Tradução de Carlota Gomes. 5. ed. Rio de Janeiro: Nova Fronteira, 1986.

BAUDELAIRE, Charles. As Flores do Mal. Edição bilíngue. Tradução, introdução e notas de Ivan Junqueira. Rio de Janeiro: Nova Fronteira, 1985. 
BATAILlE, Georges. O erotismo. Tradução de Antônio Carlos Viana. Porto Alegre: L \& PM, 1987.

COELHO, Nelly Novaes. Literatura e linguagem: a obra literária e a expressão linguística. Rio de Janeiro: José Olympio, 1974.

CORREIA, Raimundo. Versos e versões. Rio de Janeiro: Typ. e Lith. Moreira Maximino \& C., 1887.

COUTINHO, Afrânio. A literatura no Brasil. 3. ed. Rio de Janeiro: J. Olympio; Niterói: EDUFF, 1986.

FOUCAULT, Michel. História da sexualidade: o uso dos prazeres. Trad. Rio de Janeiro: Graal, 1976.

HILL, Telênia. Melhores poemas de Raimundo Correia. São Paulo: Global, 2001.

LEVIN, Orna Messer. As figurações do dândi. Um estudo sobre a obra de João do Rio. Campinas: UNICAMP, 1996.

MACHADO, Gilka. Poesias completas. Rio de Janeiro: Léo Christiano / FUNARJ, 1991.

MERQUIOR, José Guilherme. De Anchieta a Euclides: breve história da literatura brasileira. 3. ed. Rio de Janeiro: Toopbooks, 1996.

MOISÉS, Massaud. História da literatura brasileira. São Paulo: Cultrix, 1984.

MORETTO, Fúlvia (Org.). Caminhos do decadentismo francês. São Paulo: Perspectiva / Edusp, 1989.

PAZ, Otávio. A dupla chama. Tradução de Wladir Dupont. São Paulo: Siciliano, 1994.

TELES, Gilberto Mendonça. Vanguarda europeia e modernismo brasileiro. 4. ed. Petrópolis: Vozes, 1977. 